\title{
Role of the family, friends and significant others in providing social support and enhancing quality of life in cancer patients
}

\author{
L. Banovcinova and M. Baskova \\ Comenius University in Bratislava, Martin, Slovakia
}

\begin{abstract}
Cancer is a disease that may potentially affect woman's daily life, including her physical activities, career and social life. Women dealing with cancer can benefit from supportive relationships, and there was found evidence of moderating effect of social support on the harmful effect of stressful events, including life-threatening disease and patient's quality of life. The aim of this study was to examine the impact of socio-demographic factors (age, education, employment and marital status, number of children, satisfaction with finances) on perceived social support, as well as the impact of social support on quality of life. 211 gynaecologic cancer patients (cervix, endometrium - 115; breasts -52 ; ovaria - 44), between the ages of 34 and 80 were assigned for this study. The Multidimensional scale of perceived social support (MSPSS) and EORTC QoL C30 questionnaire were employed in the study. It was found that marital status, education, employment status and satisfaction with finances had an influence on social support. Positive correlation was found between total social support and family, friends and significant others subscale, and all functional subscales of quality of life questionnaire as well as overall quality of life Negative correlation was found between social support variables and most of the symptom subscales of QoL questionnaire, except for diarhea. Since the social support is one of the important factors affecting the survival of patients as well as their quality of life, healthcare professionals should also focus on building and strengthening patient's support network when working with these groups of women.
\end{abstract}

\section{Introduction}

Cancer diagnosis causes greater distress in a patient than any other disease. Predictors of this distress include young age, lower socioeconomic status, pessimism and lack of social support. According to several studies, women dealing with cancer can benefit from supportive relationships [1], and there was found evidence of moderating effect of social support on the harmful effect of stressful events, including a life-threatening disease. Social support has been identified as being protective for health and in particular for reducing cancer-related distress [2]. When considering the relationship between social support and psychological outcomes, two general models could be applied: the main and the buffering effect model. The main effect model presumes that perceived support has a direct effect on outcomes regardless of experienced stress. The buffering model suggests that when confronted with a situation of high stress, individuals cope better when receiving social support. The availability of appropriate levels of subjective support is more important than the number of contacts in the social network [3]. Social support was also shown to be very important in the prevention of anxiety, depression, and other psychological problems, which are commonly observed in 
cancer patients. Women therefore need support when coping with the stress associated with the diagnosis and treatment of cancer [4].

Cancer is a disease that may potentially affect woman's daily life, including her physical activities, career and social life [5]. Diagnosis and treatment of cancer lead to long-term worsened quality of life in cancer survivors [6]. Previous studies have identified some factors associated with QOL dimensions, such as age [7], fatigue [8], depression, anxiety [9], and perceived social support [10]. Vaz et al. [11] reported positive effect of family and psychosocial support on social relationship domain as well as psychological domain which includes positive feelings, self-esteem, spirituality/religion/personal beliefs.

According to Leung et al. [12] treatments that focus wholly on the physical aspects of cancer and that exclude psychological and social aspects leave patients vulnerable to continuing distress. This issue needs to be addressed when health professionals and their patients are discussing treatment options and available support and counselling programs.

The aim of this study was to examine the impact of socio-demographic factors (age, education, employment and marital status, number of children, satisfaction with finances) on perceived social support, as well as the impact of social support on quality of life.

\section{Methods}

211 gynaecologic cancer patients (cervix, endometrium - 115; breasts - 52; ovaria - 44), between the ages of 34 and 80 were assigned for this study. The respondents were included in the research based on the following criteria: diagnosed carcinoma of breast, ovary, cervix or endometrium; patient's consent and cooperation with filling-in the questionnaires; sufficient cognitive abilities; psychosomatic condition of the patient allowing filling in the questionnaire. Ethics approval was obtained from Ethics committee of JMF CU in Martin and all patients.

The study used a cross-sectional design to elicit information about quality of life and perceived social support. The quantitative data were collected using two questionnaires:

The 12-item Multidimensional scale of perceived social support (MSPSS) was designed to measure the perceived adequacy of support from the three sources: family (items $3,4,8$ and 11), friends (6, 7, 9 and 12), and significant other (items 1,2, 5 and 10). The values for the item were added together for each of the three dimensions. A high score means a high level of perceived social support.

EORTC QLQ-C30 incorporates five functional scales (physical, role, cognitive, emotional, and social), three symptom scales (fatigue, pain, and nausea and vomiting), a global health status / QoL scale, and a number of single items assessing additional symptoms commonly reported by cancer patients (dyspnoea, loss of appetite, insomnia, constipation and diarrhoea) and perceived financial impact of the disease.

Spearman correlation analysis was employed when processing the data.

\section{Results}

Patient's mean age was $54.34 \pm 12.33$ years. The majority (67\%) were over 50 , housewives $(54 \%)$, had secondary education level (71.6\%), were living with husband/partner (63\%), and were being treated for cancer for less than 1 year (70\%).

Social support from family and significant others were perceived in equal amounts (mean 23.04 and 22.76; SD $=4.40 ; 4.82$ respectively). Slightly lower scores were achieved by respondents in subscale of perceived social support from friends (mean 21.50; $\mathrm{SD}=4.82$ ).

Data from Quality of life questionnaire showed, that the highest scores were obtained in cognitive (mean 84.36; SD = 19.25) and physical functioning (mean 76.27; SD = 20.19), 
Table 1. Adjusted mean of social support and quality of life.

\begin{tabular}{|l|r|r|r|}
\hline & Mean & \multicolumn{1}{c|}{ SD } & Min-max \\
\hline Total social support & 67.25 & 13.11 & $32.0-84.0$ \\
\hline Family support & 23.04 & 4.40 & $9.0-28.0$ \\
\hline Friends support & 21.50 & 4.82 & $8.0-28.0$ \\
\hline Significant others support & 22.76 & 4.82 & $8.0-28.0$ \\
\hline Global QoL & 53.00 & 22.79 & $0.00-100$ \\
\hline Physical functioning & 76.27 & 20.19 & $13.33-100.0$ \\
\hline Emotional functioning & 64.06 & 24.41 & $0.00-100.0$ \\
\hline Role functioning & 71.17 & 25.76 & $0.00-100.0$ \\
\hline Cognitive functioning & 84.36 & 19.25 & $0.00-100.0$ \\
\hline Social functioning & 67.77 & 29.30 & $0.00-100.0$ \\
\hline Fatigue & 41.92 & 26.15 & $0.00-100.0$ \\
\hline Nausea and vomiting & 18.01 & 23.28 & $0.00-100.0$ \\
\hline Pain & 39.89 & 26.13 & $0.00-100.0$ \\
\hline Dyspnea & 21.01 & 24.03 & $0.00-100.0$ \\
\hline Sleep disturbance & 40.79 & 31.32 & $0.00-100.0$ \\
\hline Appetite loss & 21.64 & 25.82 & $0.00-100.0$ \\
\hline Constipation & 18.64 & 24.56 & $0.00-100.0$ \\
\hline Diarrhoea & 9.68 & 17.75 & $0.00-66.67$ \\
\hline Financial problem & 34.28 & 33.16 & $0.00-100.0$ \\
\hline
\end{tabular}

while the lowest scores were found in emotional functioning (mean 64.04; SD = 24.41) and overall quality of life (mean 53.0; $\mathrm{SD}=22.79$ ).

When the effect of socio-demographic factors on social support was examined (Table 2), it was found out that age and time since diagnosis had no effect on social support ( $\mathrm{p}>$ 0.05). Total social support as well as support from all three sources were found to be high in the group with high educational level $(\mathrm{p}<0.001)$ and women living with husband or long-term partner $(\mathrm{p}<0.001)$. Social support from friends was also quite high in employed women $(\mathrm{p}<0.05)$, while other social support variables were not influenced by women's employment status.

Spearman correlation analysis was performed between overall quality of life, five functional and symptom subscales, and the total and three subscales of social support (Table 3).

Positive correlation was found between total social support and family, friends and significant others subscale, and all functional subscales of quality of life questionnaire: that is physical functioning ( $\mathrm{p}<0.01)$, emotional functioning $(\mathrm{p}<0.01)$; social functioning ( $\mathrm{p}<0.01$ ), role functioning ( $\mathrm{p}<0.01 ; 0.05$ respectively) and cognitive functioning ( $\mathrm{p}<$ $0.01 ; 0.05$ respectively). Similarly, positive correlation was found between overall quality of life and family $(\mathrm{r}=0.250 ; \mathrm{p}<0.01)$, friends $(\mathrm{r}=0.334 ; \mathrm{p}<0.01)$, significant others $(\mathrm{r}=$ $0.274 ; \mathrm{p}<0.01)$ and total social support $(\mathrm{r}=0,312)$. Negative correlation was found between social support variables and most of the symptom subscales of QoL questionnaire, except for diarrhoea.

\section{Discussion}

Thept main aim of our study was to examine the impact of socio-demographic factors on perceived social support. It was found that marital status, education, employment status and satisfaction with finances had an influence on social support. Women that reported lower social support were living without husband or long-term partner (widows, single women), had low educational level, and were unemployed and dissatisfied with their income. 
Table 2. Effects of socio-demographic and other variables on social support.

\begin{tabular}{|c|c|c|c|c|c|c|}
\hline & & $\mathbf{N}$ & $\begin{array}{c}\text { Total } \\
\text { social } \\
\text { support }\end{array}$ & $\begin{array}{l}\text { Family } \\
\text { support }\end{array}$ & $\begin{array}{l}\text { Friends } \\
\text { support }\end{array}$ & $\begin{array}{c}\text { Significant } \\
\text { others } \\
\text { support } \\
\end{array}$ \\
\hline \multirow[t]{4}{*}{ Education level } & low & 25 & $58.24(13.56)$ & $20.56(4.22)$ & $18.28(4.79)$ & $19.4(5.35)$ \\
\hline & medium & 151 & $67.59(12.85)$ & $23.3(4.44)$ & $21.57(4.8)$ & $22.96(4.64)$ \\
\hline & high & 35 & $72.2(10.84)$ & $24.46(3.66)$ & $23.46(3.74)$ & $24.29(4.18)$ \\
\hline & $\mathrm{P}$ value & & 0.000 & 0.003 & 0.000 & 0.000 \\
\hline \multirow[t]{3}{*}{ Age } & $\leq 49$ & 69 & $68.59(13.03)$ & $23.17(4.56)$ & $22.41(4.51)$ & $23.04(4.95)$ \\
\hline & $\geq 50$ & 142 & $66.65(13.15)$ & $22.98(4.34)$ & $21.06(4.91)$ & $22.62(4.77)$ \\
\hline & $P$ value & & NS & NS & NS & NS \\
\hline \multirow{3}{*}{$\begin{array}{l}\text { Employment } \\
\text { status }\end{array}$} & Employed & 97 & $68.44(13.08)$ & $23.33(4.54)$ & $22.23(4.57)$ & $22.98(4.98)$ \\
\hline & Unemployed & 114 & $66.25(13.11)$ & $22.8(4.29)$ & $20.88(4.96)$ & 22.57 (4.7) \\
\hline & $\mathrm{P}$ value & & NS & NS & 0.043 & NS \\
\hline \multirow[t]{3}{*}{ Marital status } & Married & 133 & $69.86(12.04)$ & $23.87(4.11)$ & $22.25(4.46)$ & $23.8(4.42)$ \\
\hline & Divorced/ widow & 78 & $62.82(13.72)$ & $21.63(4.55)$ & $20.22(5.15)$ & $20.97(4.97)$ \\
\hline & $\mathrm{P}$ value & & 0.000 & 0.003 & 0.000 & 0.000 \\
\hline \multirow{3}{*}{$\begin{array}{l}\text { Time since } \\
\text { diagnosis }\end{array}$} & $\leq 1$ year & 147 & $68.03(12.54)$ & $23.36(4.21)$ & $21.7(4.66)$ & $23.03(4.68)$ \\
\hline & $>1$ year & 64 & 65.47 (14.29) & $22.31(4.77)$ & $21.03(5.17)$ & $22.13(5.1)$ \\
\hline & $P$ value & & NS & NS & NS & NS \\
\hline
\end{tabular}

Table 3. Spearman correlation between quality of life and social support variables.

\begin{tabular}{|l|c|c|c|c|}
\hline & $\begin{array}{l}\text { Total social } \\
\text { support }\end{array}$ & $\begin{array}{l}\text { Family } \\
\text { support }\end{array}$ & $\begin{array}{l}\text { Friends } \\
\text { support }\end{array}$ & $\begin{array}{l}\text { Significant } \\
\text { others support }\end{array}$ \\
\hline Global QoL & $0.312^{* *}$ & $0.250^{* *}$ & $0.334^{* *}$ & $0.274^{* *}$ \\
\hline Physical functioning & $0.246^{* *}$ & $0.236^{* *}$ & $0.253^{* *}$ & $0.247^{* *}$ \\
\hline Emotional functioning & $0.284^{* *}$ & $0.208^{* *}$ & $0.352^{* *}$ & $0.233^{* *}$ \\
\hline Role functioning & $0.192^{* *}$ & $0.176^{*}$ & $0.226^{* *}$ & $0.181^{* *}$ \\
\hline Cognitive functioning & $0.199^{* *}$ & $0.173^{*}$ & $0.227^{* *}$ & $0.165^{*}$ \\
\hline Social functioning & $0.283^{* *}$ & $0.250^{* *}$ & $0.297^{* *}$ & $0.276^{* *}$ \\
\hline Fatigue & $-0.242^{* *}$ & $-0.207^{* *}$ & $-0.261^{* *}$ & $-0.252^{* *}$ \\
\hline Nausea and vomiting & $-0.156^{*}$ & -0.107 & $-0.188^{* *}$ & $-0.150^{*}$ \\
\hline Pain & $-0.273^{* *}$ & $-0.243^{* *}$ & $-0.287^{* *}$ & $-0.284^{* *}$ \\
\hline Dyspnea & $-0.340^{* *}$ & $-0.310^{* *}$ & $-0.335^{* *}$ & $-0.336^{* *}$ \\
\hline Sleep disturbance & $-0.339^{* *}$ & $-0.312^{* *}$ & $-0.320^{* *}$ & $-0.320^{* *}$ \\
\hline Appetite loss & $-0.216^{* *}$ & $-0.163^{*}$ & $-0.227^{* *}$ & $-0.238^{* *}$ \\
\hline Constipation & $-0.195^{* *}$ & -0.135 & $-0.247^{* *}$ & $-0.147^{*}$ \\
\hline Diarrhea & -0.010 & 0.005 & -0.043 & 0.024 \\
\hline Financial problem & $-0.292^{* *}$ & $-0.276^{* *}$ & $-0.293^{* *}$ & $-0.248^{* *}$ \\
**Correlation is significant at the 0.01 level (2-tailed). \\
*Correlation is significant at the 0.05 level (2-tailed).
\end{tabular}

The importance of spousal support for women with breast cancer was highlighted in findings of Leung et al. [12]. In their study, married or partnered women had higher levels of social support and better QoL. As they stated, those with higher incomes generally have larger social networks, and unemployment has a negative effect on marital and family support.

Although no statistically significant correlation was found between time since diagnosis and perceived social support, with prolonged care-giving burden and expectations 
that patients recover after treatment, supportive attitudes may weaken after primary treatment [13]. Those with more years since diagnosis trended toward lower perceived social support in this study. Patients' family and their loved ones can be very supportive during early illness trajectories. On the other hand, one longitudinal study on QOL and social support in cancer patients reported that network size and the amount of received emotional support decreased somewhat over time [14]. This decrease may be related to a reduction in the availability of needed support as well as a reduction in the perceived quality of support, when available [15].

Positive correlation was found between total social support and family, friends and significant others subscale, and all functional subscales of quality of life questionnaire as well as overall quality of life.

In study carried by Eom et al. [13], perceived social support was found to be associated with mental health and QOL; specifically, low perceived social support was associated with low QOL in this study. This result was consistent with previous studies that showed that higher perceived social support was associated with a higher QOL [16;17]. Previous research reported that emotional support is positively correlated with QOL in patients with cancer. In a greatly stressful event such as cancer, perceived social support can improve QOL. On the contrary, in the study conducted by Salonen et al. [18], it was found, that receiving more support from network increased the risk of negative changes in global QoL. As authors suggested it is possible that women, especially in early stages of the disease, do not need or expect to receive social support from their network. Therefore, they may reject any support offered, because they are not responsive enough and consequently experience it in negative way.

\section{Conclusion}

Since the social support is one of the important factors affecting the survival of patients as well as their quality of life, healthcare professionals should also focus on building and strengthening patient's support network when working with these groups of women.

This work was supported by project "Virtual and Simulation Tuition as a New Form of Education at JFM CU in Martin”, ITMS: 26110230071, co-funded from EU sources and European Social Fund.

\section{References}

[1] Parker, P. A., Baile, W. F., de Moor, C., \& Cohen, L. Psychosocial and demographic predictors of quality of life in a large sample of cancer patients. Psycho-oncology 12, 183-193 (2003).

[2] Badger, TA, Segrin, C., Hepworth, JT., Pasvogel, A., Weihs, K., Lopez, AM. Telephone-delivered health education and interpersonal counselling improve quality of life for Latinas with breast cancer and their supportive partners. Psycho-Oncology 22: 1035-1042 (2011).

[3] Cohen, S., Wills, TA. Stress, social support, and the buffering hypothesis. Psychol Bull, 98: 310-357 (1985).

[4] Friedman, LC, Kalidas, M, Elledge, R. et al. Optimism, social support and psychosocial functioning among women with breast cancer. Psychoonkology, 15: 595-603 (2006).

[5] Ozkan, S., Ogce, F. Importance of social support for functional status in breast cancer patients. Asian Pacific Journal of Cancer Prevention, 9: 601-604 (2008). 
[6] Ganz, PA, Desmond, KA, Leedham, B., Rowland, JH, Meyerowitz, BE, Belin, TR. Quality of life in long-term, disease-free survivors of breast cancer: a follow-up study. J Natl Cancer Inst, 94: 39-49 (2002).

[7] Hopwood, P., Haviland, J., Mills, J. et al. The impact of age and clinical factors on quality of life in early breast cancer: an analysis of 2208 women recruited to the UK START Trial (Standardization of Breast Radiotherapy Trial). Breast, 16(3): 241-251 (2007).

[8] Kim, S. H., Son, B.H., Hwang, S.Y. et al. Fatigue and depression in Disease-Free Breast Cancer Survivirs: Prevalence, Correlates, and Assoc iation with Quality of Life. Journal of Pain and Symptom Management, 35(6), 644-655 (2008).

[9] Burges, C., Cornelius, V., Love, S. et al. Depression and anxiety in women with early breast cancer: Five year observational cohort study. British Medical Journal, 330: 702 (2005).

[10] Sammarco, A. Quality of life among older survivors of breast cancer. Cancer Nursing, 26(6): 431-438 (2003).

[11] Vaz, A.F., Pinto-Neto, A.M., Conde, D.M. et al. Quality of life of women with gynecologic cancer: associated factors. Arch Gynecol Obstet, 276: 583-589 (2007).

[12] Leung, J., Pachana, N.A., McLaughlin, D. Social support and quality of life in women with breast cancer: a longitudinal study. Psycho-Oncology 23: 1014-1020 (2014).

[13] Eom, ChS, Shin, DW, Kim, SY, Yang, HK et al. Impact of perceived social support on the mental health and health-related quality of life in cancer patients: results from a nationwide, multicenter survey in South Korea. Psycho-Oncology, 22: 1283-1290 (2013).

[14] Courtens AM, Stevens FC, Crebolder HF et al. Longitudinal study on quality of life and social support in cancer patients. Cancer Nursing, 19:162-169 (1996).

[15] Arora, NK., Finney Rutten, LJ, Gustafson, DH, Moser, R, Hawkins, RP. Perceived helpfulness and impact of support provided by family, friends, and health care providers to women newly diagnosed with breast cancer. Psycho-Oncology, 16: 474486 (2007).

[16] Smith SK, Crespi CM, Petersen L et al. The impact of cancer and quality of life for posttreatment non-Hodgkin lymphoma survivors. Psycho-Oncology, 19: 1259-1267 (2010).

[17] Zhou ES, Penedo FJ, Lewis JE et al. Perceived stress mediates the effects of social support on health-related quality of life among men treated for localized prostate cancer. J. Psychosom. Res. 69: 587-590 (2010).

[18] Salonen,P, Tarkka, MT, Kellokumpu-Lehtinen, PL, Koivisto, AM, Aalto P, Kaunonen, M. Effect of social support on changes in quality of life in early breast cancer patients: a longitudinal study. Scandinavian journal of Caring Sciences, 27(2): 396-405 (2012). 